Bull. Chem. Soc. Ethiop. 2012, 26(2), 279-285.

Printed in Ethiopia

DOI: http://dx.doi.org/10.4314/bcse.v26i2.11

ISSN 1011-3924

(c) 2012 Chemical Society of Ethiopia

\title{
THEORETICAL MOLECULAR STRUCTURE, VIBRATIONAL FREQUENCIES AND NMR INVESTIGATIONS OF 2-[(1E)-2-AZA-2-(5-METHYL(2-PYRIDYL)ETHENYL)]-4-BROMOBENZEN-1-OL
}

\author{
Metin Bilge ${ }^{1}$, Hasan Bircan ${ }^{2}$, Özgür Alver ${ }^{3}$ and Cemal Parlak ${ }^{2 *}$ \\ ${ }^{1}$ Department of Physics, Science Faculty, Ege University, 35100, İzmir, Turkey \\ ${ }^{2}$ Department of Physics, Dumlupınar University, 43100, Kütahya, Turkey \\ ${ }^{3}$ Department of Physics, Anadolu University, 26470, Eskişehir, Turkey
}

(Received July 12, 2010; revised September 13, 2011)

\begin{abstract}
The normal mode frequencies and corresponding vibrational assignments, ${ }^{1} \mathrm{H}$ and ${ }^{13} \mathrm{C}$ NMR chemical shifts and structural parameters (bond lengths, bond and dihedral angles) of 2-[(1E)-2-aza-2-(5methyl(2-pyridyl)ethenyl)]-4-bromobenzen-1-ol (2mpe-4bb) Schiff base compound have been theoretically examined by means of Hartree-Fock (HF) and Becke-3-Lee-Yang-Parr (B3LYP) density functional methods with 6-31G(d) and 6-311++G(d,p) basis sets. Furthermore, reliable vibrational assignments have made on the basis of potential energy distribution (PED) calculated and the thermodynamics functions, highest occupied and lowest unoccupied molecular orbitals (HOMO and LUMO) of 2 mpe- $4 \mathrm{bb}$ have been predicted. Theoretical results have been successfully compared with available experimental data in the literature. Regarding the calculations, $2 \mathrm{mpe}-$ $4 \mathrm{bb}$ prefers enol-imine form and DFT method is superior to HF approach except for predicting bond lengths.
\end{abstract}

KEY WORDS: Schiff bases, Normal mode frequencies, HF, DFT, NMR

\section{INTRODUCTION}

Compounds with the structure $\mathrm{XC}=\mathrm{NY}$ are known as Schiff bases, which are usually synthesized from the condensation of primary amines and active carbonyl groups. Some Schiff bases are used as starting materials in the reactions of important drugs, such as antibiotics, antiallergic and antitumor substances [1,2]. Schiff bases have been widely used as ligand in the coordination chemistry [3] and they also show antibacterial [4, 5], antifungal [6] and herbicidal [7] activities. In these compounds, two types of intermolecular hydrogen bonds (either O-H...N or $\mathrm{O} \ldots \mathrm{H}-\mathrm{N}$ ) between the $\mathrm{OH}$ group and the imine nitrogen can exist $[8,9]$. According to the formation of hydrogen bonds, tautomeric equilibrium prefers phenol-imine $(\mathrm{O}-\mathrm{H} \ldots \mathrm{N})$ or ketoamine $(\mathrm{O} \ldots \mathrm{H}-\mathrm{N})$ form.

Density functional theory (DFT) has wide popularity as a cost effective general procedure for studying the physical properties of compounds. Unlike Hartree Fock (HF) theory, DFT recovers electron correlation in the self-consistent Kohn-Sham procedure through the functions of electron density, so it is a cost effective and reliable method [10-17]. The DFT/B3LYP model exhibits good performance on electron affinities, excellent performance on bond energies and reasonably good performance on vibrational frequencies, geometries and chemical shieldings of compounds [10-17].

In the previous publication, 2mpe-4bb Schiff base compound $\left(\mathrm{C}_{13} \mathrm{H}_{11} \mathrm{BrN}_{2} \mathrm{O}\right)$ was synthesized by $\mathrm{Dal}$ and coworkers [9]. They also reported some selected geometric parameters and vibrational frequencies of $2 \mathrm{mpe}-4 \mathrm{bb}$ together with its full ${ }^{1} \mathrm{H}$ and ${ }^{13} \mathrm{C}$ NMR chemical shifts in the same study. Even though, many Schiff base compounds have wide applications in the medical and pharmaceutical industry, there are few theoretical data for their spectroscopic spectra in literature. A detailed quantum chemical study will aid in making definitive assignments to the fundamental normal modes and chemical shifts and in clarifying the obtained

*Corresponding author. E-mail: cparlak20@gmail.com 
experimental data for the title compound. Furthermore, the presented data as theoretically may be helpful in context of the further studies of $2 \mathrm{mpe}-4 \mathrm{bb}$. For the above goals, we have calculated structural parameters, thermodynamics functions, vibrational frequencies together with PED, HOMO and LUMO data, ${ }^{1} \mathrm{H}$ and ${ }^{13} \mathrm{C}$ NMR chemical shifts of 2 mpe-4bb using HF and DFT methods with 6-31G(d) and 6-311++G(d,p) basis sets and compared with available experimental values.

\section{CALCULATIONS}

For the calculations, the title compound was first optimized by HF and DFT methods with 6$31 \mathrm{G}(\mathrm{d})$ basis set in the gas phase together with the keyword volume (Figure 1). The energy of this compound with the latter method was found lower than the former (Table 1). After optimization, the vibrational frequencies of $2 \mathrm{mpe}-4 \mathrm{bb}$ were calculated using the same methods and the basis set with the keyword freq and pop, and then scaled by 0.8929 for HF and 0.9613 for DFT [11-14] to generate the corrected frequencies. PED calculations; which show the relative contributions of the redundant internal coordinates to each normal vibrational mode of the molecule and thus make it possible to describe the character of each mode numerically; were carried out by the VEDA 4 (Vibrational Energy Distribution Analysis) program [18].

For the NMR calculations, the title compound was first fully optimized at HF and DFT methods using 6-31G(d) basis set in chloroform with the IEFPCM method [14-17] (Table 1). After optimization, ${ }^{1} \mathrm{H}$ and ${ }^{13} \mathrm{C}$ NMR chemical shifts $\left(\delta_{\mathrm{H}}\right.$ and $\left.\delta_{\mathrm{C}}\right)$ of $2 \mathrm{mpe}-4 \mathrm{bb}$ were calculated using the GIAO method [14-17] for the solvent given above at the HF/6-311++G(d,p) and DFT/6-311++G(d,p) levels under the keyword nmr. Relative chemical shifts were then estimated using the corresponding tetramethylsilan (TMS) shieldings calculated in advance at the same theoretical levels as the reference. Calculated ${ }^{1} \mathrm{H}$ and ${ }^{13} \mathrm{C}$ isotropic chemical shieldings for the reference at the DFT/6-311++G(d,p)//6-31G(d) and HF/6-311++G(d,p)// 6-31G(d) levels are given in Table 2 together with the experimental values [19,20]. All the calculations were performed using Gaussian 03 program on a personal computer and Gauss View program was used for visualization of the structure $[21,22]$.

\section{RESULTS AND DISCUSSION}

2mpe-4bb Schiff base has either enol-imine $(\mathrm{O}-\mathrm{H} \ldots \mathrm{N})$ or keto-amine $(\mathrm{O} \ldots \mathrm{H}-\mathrm{N})$ conformation. Dal and coworkers determined the crystal structure of $2 \mathrm{mpe}-4 \mathrm{bb}$ and showed that it belongs to the enol-imine form [9]. The optimized molecular structure and numbering of the atoms for $2 \mathrm{mpe}-4 \mathrm{bb}$ are given in Figure 1.

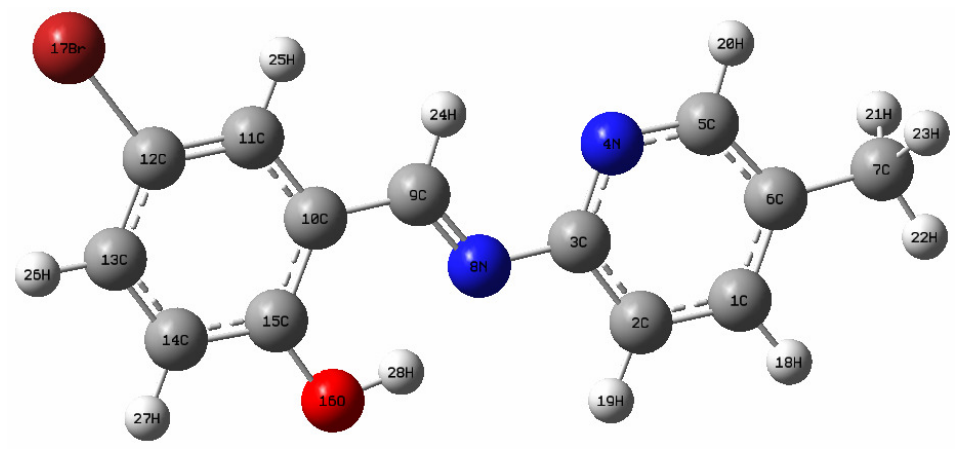

Figure 1. Optimized structure and numbering of $2 \mathrm{mpe}-4 \mathrm{bb}$.

Bull. Chem. Soc. Ethiop. 2012, 26(2) 
Several thermodynamics parameters, capacity, zero point energy, entropy etc., calculated by $\mathrm{HF}$ and DFT with 6-31G(d) and 6-31++G(d,p) basis sets are presented in Table 1. The variation in the zero point vibrational energy seems to be insignificant for the same method in different medium. The change in entropy of $2 \mathrm{mpe}-4 \mathrm{bb}$ is at room temperature. The dipole moment is expected to be larger in solution than the corresponding dipole moment in the gas phase. This situation is clearly observed in Table 1 and the dipole moment increases gradually from lower to higher dielectric. The increases on going from gas to chloroform as non-polar solvent are between $13 \%$ and $18 \%$.

Table 1. Some general and thermodynamic parameters of $2 \mathrm{mpe}-4 \mathrm{bb}$ in the different medium.

\begin{tabular}{|l|c|c|}
\hline Medium & HF/6-31G(d) & B3LYP/6-31G(d) \\
\hline Gas phase & 182.769 & 195.283 \\
\hline Molar volume $\left(\mathrm{cm}^{3} / \mathrm{mol}\right)$ & 5.09 & 5.19 \\
\hline Recommend a $(\AA)$ & -3252.162441 & -3258.279995 \\
\hline$\Delta \mathrm{G}($ Hartree$)$ & 144.63443 & 134.31400 \\
\hline Zero point vibrational energy, $(\mathrm{kcal} / \mathrm{mol})$ & 121.410 & 122.969 \\
\hline Entropy $(\mathrm{cal} / \mathrm{mol} \mathrm{K})$ & 50.405 & 53.910 \\
\hline Heat capacity $(\mathrm{cal} / \mathrm{mol} \mathrm{K})$ & 3.8066 & 3.9631 \\
\hline Dipole moment $($ Debye $)$ & \multicolumn{2}{|l|}{} \\
\hline Chloroform $(\varepsilon=4.9)$ & -3252.174983 & -3258.289750 \\
\hline$\Delta \mathrm{G}($ Hartree $)$ & 143.63443 & 133.62346 \\
\hline Zero point vibrational energy $(\mathrm{kcal} / \mathrm{mol})$ & 123.574 & 123.915 \\
\hline Entropy $(\mathrm{cal} / \mathrm{mol} \mathrm{K})$ & 50.638 & 54.085 \\
\hline Heat capacity $(\mathrm{cal} / \mathrm{mol} \mathrm{K})$ & 4.3076 & 4.6749 \\
\hline Dipole moment $($ Debye $)$ &
\end{tabular}

Table 2. Calculated and experimental isotropic shieldings (ppm) of TMS as reference.

\begin{tabular}{|l|c|c|}
\hline Method & ${ }^{1} \mathrm{H} / \mathrm{TMS}$ & ${ }^{13} \mathrm{C} / \mathrm{TMS}$ \\
\hline $\mathrm{HF} / 6-311++\mathrm{G}(\mathrm{d}, \mathrm{p}) / / 6-31 \mathrm{G}(\mathrm{d})$ & 32.44 & 196.45 \\
\hline B3LYP/6-311++G(d,p)//6-31G(d) & 31.87 & 183.76 \\
\hline Experimental & $30.84[19]$ & $188.10[20]$ \\
\hline
\end{tabular}

The optimized structural parameters (bond lengths and angles) by HF and DFT with 6$31 \mathrm{G}(\mathrm{d})$ basis set are listed in Table 3 and compared with available experimental crystal geometry of $2 \mathrm{mpe}-4 \mathrm{bb}$ [9]. It can be easily seen that the skeleton of $2 \mathrm{mpe}-4 \mathrm{bb}$ is planar since the experimental dihedral angle between the phenyl and pyridine rings is $4.1^{\circ}$ [9]. Related theoretical dihedral angles are found as $3.6^{\circ}$ for DFT and $3.2^{\circ}$ for HF. Phenolic $\mathrm{H}$ atom $(\mathrm{O}-\mathrm{H}$ : $0.820 \AA$ ) is positioned at the distance not favorable for the formation of keto-imine form [9]. This bond length has been computed as about $0.955 \AA$. This compound has a short intermolecular O-H...N hydrogen bond (H28-N8: $1.873 \AA$ A, N8-O16: $2.600 \AA$, N8-H28-O16: $147.1^{\circ}$ ) which means that it is in enol-imine form. These experimental values have been supported by theoretical results and calculated as $1.880 \AA$, $2.708 \AA, 145.1^{\circ}$ for $\mathrm{HF}$ and $1.773 \AA$, $2.633 \AA, 147.7^{\circ}$ for DFT, respectively. In addition, the experimental C-O bond (1.344 $\AA$ ) which has a single bond character is comparable to the single bond values in enols (1.333 $\AA$ ) [23]. This bond length has been calculated as $1.328 \AA$ for HF and 1.339 $\AA$ for DFT (Table 3). Considering the general compliance between the experimental and calculated structural parameters, it can be concluded that $2 \mathrm{mpe}-4 \mathrm{bb}$ compound prefers enol-imine tautomeric conformation. 
Table 3. Some experimental and calculated structural parameters of $2 \mathrm{mpe}-4 \mathrm{bb}$.

\begin{tabular}{|c|c|c|c|}
\hline Parameters & Exp. [9] & $\mathrm{HF}$ & B3LYP \\
\hline \multicolumn{4}{|l|}{ Bond lengths $(\AA \dot{A})$} \\
\hline $\mathrm{C}(10)-\mathrm{C}(11)$ & 1.402 & 1.398 & 1.409 \\
\hline $\mathrm{C}(11)-\mathrm{C}(12)$ & 1.368 & 1.372 & 1.382 \\
\hline $\mathrm{C}(12)-\mathrm{C}(13)$ & 1.381 & 1.390 & 1.401 \\
\hline $\mathrm{C}(13)-\mathrm{C}(14)$ & 1.376 & 1.376 & 1.387 \\
\hline $\mathrm{C}(14)-\mathrm{C}(15)$ & 1.389 & 1.394 & 1.404 \\
\hline $\mathrm{C}(15)-\mathrm{C}(10)$ & 1.406 & 1.403 & 1.424 \\
\hline $\mathrm{C}(9)-\mathrm{C}(10)$ & 1.448 & 1.464 & 1.448 \\
\hline $\mathrm{C}(3)-\mathrm{N}(4)$ & 1.335 & 1.321 & 1.342 \\
\hline $\mathrm{C}(6)-\mathrm{C}(7)$ & 1.508 & 1.510 & 1.508 \\
\hline $\mathrm{N}(8)-\mathrm{C}(9)$ & 1.283 & 1.265 & 1.295 \\
\hline $\mathrm{N}(8)-\mathrm{C}(3)$ & 1.417 & 1.407 & 1.408 \\
\hline $\mathrm{N}(4)-\mathrm{C}(5)$ & 1.336 & 1.316 & 1.331 \\
\hline $\mathrm{O}(16)-\mathrm{H}(28)$ & 0.820 & 0.935 & 0.976 \\
\hline $\mathrm{O}(16)-\mathrm{C}(15)$ & 1.344 & 1.328 & 1.339 \\
\hline $\operatorname{Br}(17)-C(12)$ & 1.894 & 1.898 & 1.903 \\
\hline \multicolumn{4}{|l|}{ Bond angles $\left({ }^{\circ}\right)$} \\
\hline $\mathrm{O}(16)-\mathrm{C}(15)-\mathrm{C}(10)$ & 122.0 & 122.9 & 122.1 \\
\hline $\mathrm{O}(16)-\mathrm{C}(15)-\mathrm{C}(14)$ & 118.2 & 117.6 & 118.4 \\
\hline $\mathrm{N}(8)-\mathrm{C}(9)-\mathrm{C}(10)$ & 121.8 & 122.7 & 121.7 \\
\hline $\mathrm{C}(3)-\mathrm{N}(8)-\mathrm{C}(9)$ & 120.2 & 120.0 & 120.1 \\
\hline
\end{tabular}

Regarding the calculations the largest difference between the experimental and calculated bond lengths (angles) is $0.115 \AA\left(0.9^{\circ}\right)$ for HF and $0.156 \AA\left(0.2^{\circ}\right)$ for DFT with the $6-31 \mathrm{G}(\mathrm{d})$ basis set. The correlation values between the experimental and calculated bond lengths - angles are found to be $0.98217\left(R_{\text {calc. }}=0.906 R_{\text {exp. }}+0.134\right)-0.99323\left(A_{\text {calc. }}=1.420 A_{\text {exp. }}-50.378\right)$ for $\mathrm{HF} / 6-31 \mathrm{G}(\mathrm{d})$ and $0.97765\left(\mathrm{R}_{\text {calc. }}=0.864 \mathrm{R}_{\text {exp. }}+0.204\right)-0.99427\left(\mathrm{~A}_{\text {calc. }}=0.955 \mathrm{~A}_{\text {exp. }}+5.399\right)$ for DFT/6-31G(d). It can be seen that HF method correlates well for the bond lengths while DFT shows well correlation for the bond angles compared with the other method. We note that the experimental and calculated results belong to solid and gaseous phases, respectively, for the structural parameters and vibrational frequencies.

2 mpe- 4 bb consists of 28 atoms, so it has 78 normal mode frequencies and belongs to the $C_{1}$ point group with the only identity (E) symmetry element or operation. Some calculated and corrected vibrational wavenumbers and corresponding vibrational assignments with PED data for 2mpe-4bb at HF and DFT with 6-31G(d) basis set are given in Table 4, together with the available experimental data, for comparison. The correction factors $(0.8929$ for $\mathrm{HF}$ and 0.9613 for DFT), widely used in the literature [11-14], are applied to generate the corrected wavenumbers (Table 4). The $\mathrm{OH}$ stretching band of $2 \mathrm{mpe}-4 \mathrm{bb}$ was observed at $3426 \mathrm{~cm}^{-1}$ and this implies that the $\mathrm{H}$ atom has intermolecular hydrogen bonding [9]. The corrected wavenumber of the $\mathrm{OH}$ stretching mode for $\mathrm{HF}$ is $3439 \mathrm{~cm}^{-1}$ whereas this mode is $3428 \mathrm{~cm}^{-1}$ for DFT. The CN stretching band observed at $1610 \mathrm{~cm}^{-1}$ [9], in agreement with values reported in the literature for pyridine derived Schiff base, is theoretically predicted at $1663 \mathrm{~cm}^{-1}$ and 1613 $\mathrm{cm}^{-1}$ for HF and DFT, respectively. 2mpe-4bb compound with strong band at $1280 \mathrm{~cm}^{-1}$ possesses highest percentage of enol-imine form due to the stabilization of phenolic $\mathrm{CO}$ bond [9]. The CO mode of $2 \mathrm{mpe}-4 \mathrm{bb}$ has been computed at $1283 \mathrm{~cm}^{-1}$ for HF and $1284 \mathrm{~cm}^{-1}$ for DFT. 
Table 4. Selected vibrational modes of 2mpe-4bb calculated at HF and DFT methods with 6-31G(d).

\begin{tabular}{|l|c|c|c|c|c|}
\hline Mode/Assignment/PED (\%) & $\begin{array}{c}\text { Experimental } \\
\text { frequency }^{\mathrm{a}}\end{array}$ & $\begin{array}{c}\text { Calculated } \\
\text { frequency }\end{array}$ & $\begin{array}{c}\text { Corrected } \\
\text { frequency }^{\mathrm{b}}\end{array}$ & IR intensity $^{\mathrm{c}}$ & $\begin{array}{c}\text { Raman } \\
\text { activity }^{\mathrm{d}}\end{array}$ \\
\hline $\mathrm{HF}$ & & & & & \\
\hline $\mathrm{V}_{1} / \mathrm{O}-\mathrm{H}$ stretching / 100 & $3426 \mathrm{~s}$ & 3851 & 3439 & 386.91 & 38.60 \\
\hline $\mathrm{V}_{12} / \mathrm{C}=\mathrm{N}$ stretching / 65 & $1610 \mathrm{~s}$ & 1862 & 1663 & 535.52 & 917.99 \\
\hline $\mathrm{V}_{15} / \mathrm{C}=\mathrm{C}$ stretching / 59 & $1587 \mathrm{~s}$ & 1780 & 1589 & 17.58 & 10.12 \\
\hline $\mathrm{V}_{27} / \mathrm{C}-\mathrm{O}$ stretching / 29 & $1280 \mathrm{~s}$ & 1437 & 1283 & 83.14 & 57.55 \\
\hline \multicolumn{1}{|c|}{$\mathrm{B} 3 \mathrm{LYP}$} & & & & & \\
\hline $\mathrm{v}_{1} / \mathrm{O}-\mathrm{H}$ stretching / 84 & $3426 \mathrm{~s}$ & 3566 & 3428 & 186.16 & 54.89 \\
\hline $\mathrm{V}_{12} / \mathrm{C}=\mathrm{N}$ stretching / 75 & $1610 \mathrm{~s}$ & 1678 & 1613 & 72.33 & 170.16 \\
\hline $\mathrm{V}_{15} / \mathrm{C}=\mathrm{C}$ stretching / 52 & $1587 \mathrm{~s}$ & 1647 & 1583 & 23.27 & 22.99 \\
\hline $\mathrm{V}_{27} / \mathrm{C}-\mathrm{O}$ stretching / 55 & $1280 \mathrm{~s}$ & 1336 & 1284 & 60.71 & 38.31 \\
\hline
\end{tabular}

${ }^{\mathrm{a}}$ Reference [9]. ${ }^{\mathrm{b}}$ Raw calculated frequencies multiplied by 0.8929 (HF) and 0.9613 (B3LYP) correction factors [11-14]. 'Units of IR intensity are $\mathrm{km} / \mathrm{mol}$. ${ }^{\mathrm{d}}$ Units of Raman scattering activity are $\AA^{4} / \mathrm{amu}$. PED data are taken from VEDA4.

The largest difference between the experimental and corrected wavenumbers is $53 \mathrm{~cm}^{-1}$ for $\mathrm{HF}$ and $4 \mathrm{~cm}^{-1}$ for DFT using the $6-31 \mathrm{G}(\mathrm{d})$ basis set. The correlation values between the computed and experimental wavenumbers are found to be $0.99940\left(v_{\text {calc. }}=0.893 v_{\text {exp. }}-0.397\right)$ for HF/6-31G(d) and $0.99999\left(v_{\text {calc. }}=0.961 v_{\text {exp. }}-0.386\right)$ for DFT/6-31G(d). It can be seen that the DFT/6-31G(d) method is better than HF/6-31G(d).

The HOMO and LUMO orbitals are main orbital take part in chemical stability. The HOMO describes the ability to donate an electron and LUMO as an electron acceptor. The absorption of electronic transition is defined from the ground to the first excited state. In other words, the transitions can be described from HOMO to LUMO. The HOMO is located over all carbon, N4 and $\mathrm{Br} 17$ atoms in 2mpe-4bb while the LUMO is dominated for N8 and $\mathrm{O} 16$ atoms. The atomic compositions of frontier molecular orbital and their orbital energies are shown in Figure 2.

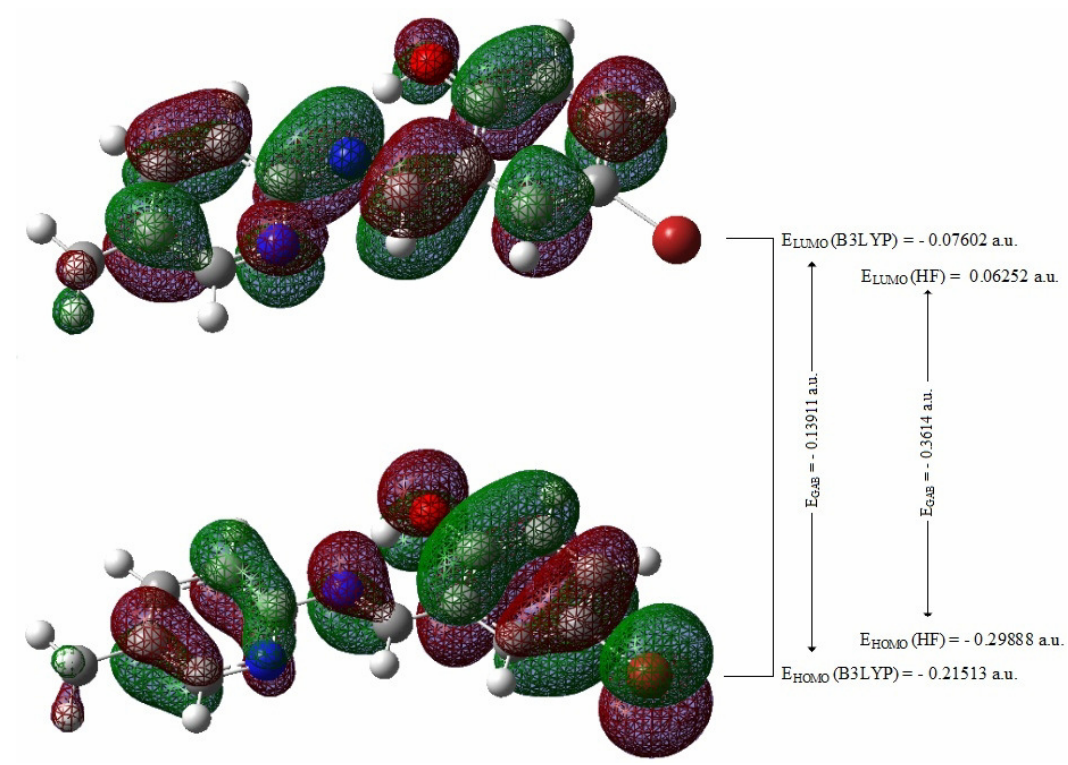

Figure 2. Atomic orbital compositions of the frontier molecular orbital for $2 \mathrm{mpe}-4 \mathrm{bb}$.

Bull. Chem. Soc. Ethiop. 2012, 26(2) 
We have also calculated the ${ }^{1} \mathrm{H}$ and ${ }^{13} \mathrm{C}$ NMR chemical shifts of the title compound. Then, we have compared the theoretical and experimental chemical shifts of $2 \mathrm{mpe}-4 \mathrm{bb}$. The results are shown in Table 5. According to the results, the calculated chemical shifts are in compliance with the experimental results. The largest difference between the experimental and calculated ${ }^{1} \mathrm{H}$ $-{ }^{13} \mathrm{C}$ chemical shifts is $0.68-7.8 \mathrm{ppm}$ for $\mathrm{HF}$ and $0.46-7.0 \mathrm{ppm}$ for DFT with the 6$311++\mathrm{G}(\mathrm{d}, \mathrm{p})$ basis set. The correlation values for proton - carbon chemical shifts are found to be $0.98102\left(\delta_{\text {calc. }}=0.930 \delta_{\text {exp. }}+0.986\right)-0.99803\left(\delta_{\text {calc. }}=1.048 \delta_{\text {exp. }}-0.779\right)$ for $\mathrm{HF} / 6-$ $311++\mathrm{G}(\mathrm{d}, \mathrm{p})$ and $0.99379\left(\delta_{\text {calc. }}=0.977 \delta_{\text {exp. }}+0.420\right)-0.99857\left(\delta_{\text {calc. }}=1.041 \delta_{\text {exp. }}-0.825\right)$ for DFT/6-311++G(d,p). It can be seen that the results of DFT method are better than HF for predicting NMR properties.

Table 5. Experimental and calculated ${ }^{13} \mathrm{C}$ and ${ }^{1} \mathrm{H}$ NMR chemical shifts (ppm) of $2 \mathrm{mpe}-4 \mathrm{bb}$.

\begin{tabular}{|c|c|c|c|}
\hline Nucleus & Exp. [9] & HF & B3LYP \\
\hline C1 & 138.9 & 146.5 & 145.9 \\
\hline C2 & 120.0 & 125.0 & 123.8 \\
\hline C3 & 154.8 & 161.1 & 161.7 \\
\hline C5 & 149.3 & 155.7 & 155.9 \\
\hline C6 & 132.9 & 136.2 & 134.9 \\
\hline C7 & 18.2 & 18.4 & 18.8 \\
\hline C9 & 162.4 & 168.8 & 168.5 \\
\hline C10 & 120.5 & 122.3 & 123.6 \\
\hline C11 & 135.3 & 141.3 & 141.5 \\
\hline C12 & 110.6 & 118.1 & 114.6 \\
\hline C13 & 136.1 & 143.8 & 140.3 \\
\hline C14 & 119.4 & 122.7 & 121.4 \\
\hline C15 & 160.8 & 168.6 & 165.3 \\
\hline Nucleus & Exp. [9] & HF & B3LYP \\
\hline H18 & $7.50-7.60$ & 8.31 & 7.81 \\
\hline H19 & 7.30 & 7.66 & 7.55 \\
\hline H20 & 8.34 & 8.94 & 8.80 \\
\hline CH3 & 2.40 & 2.51 & 2.41 \\
\hline H24 & 9.50 & 10.11 & 9.91 \\
\hline H25 & $7.50-7.60$ & 8.42 & 7.95 \\
\hline H26 & 7.55 & 8.21 & 7.75 \\
\hline H27 & 6.93 & 7.56 & 7.38 \\
\hline H28 & 13.60 & 12.92 & 13.33 \\
\hline
\end{tabular}

\section{CONCLUSIONS}

The theoretical investigations of 2mpe-4bb Schiff base compound are successfully performed by using quantum chemical calculations such as HF and DFT. In conclusion, following results can be summarized: (i) calculated bond lengths are, in general, slightly bigger than experimental ones which are possibly due to the shortening of the bond lengths of the title molecule during the experimental measurements conducted at very low temperature. However, similar generalizations are not possible for bond angles; (ii) any differences observed between the experimental and calculated wavenumbers could be due to the fact that the calculations are performed for single molecule in the gaseous state contrary to the experimental values recorded in the presence of intermolecular interactions; (iii) for the structural bond lengths, HF method is better than DFT whereas DFT method with B3LYP functional and 6-31G(d) or 6-311++G(d,p) basis sets is better than HF for the bond angles, vibrational wavenumbers and NMR chemical 
Molecular structure of 2-[(1e)-2-aza-2-(5-methyl(2-pyridyl)ethenyl)]-4-bromobenzen-1-ol 285

shifts; and (iv) all the theoretical results have supported the conclusion obtained in the experimental studies that $2 \mathrm{mpe}-4 \mathrm{bb}$ is in enol-imine isomer.

\section{REFERENCES}

1. Yu, S.Y.; Wang, S.X.; Luo, Q.H.; Wang, L.F. Polyhedron 1993, 12, 1093.

2. Rekha, S; Nagasundara K.R. Indian. J. Chem. A 2006, 45, 2421.

3. Calligaris, M.; Randaccio, L. in Comprehensive Coordination Chemistry, Vol. 2, Wilkinson, G. (Ed.), Pergamon: Oxford; 1987.

4. Karia, F.D.; Parsania, P.H. Asian J. Chem. Soc. 1999, 11, 991.

5. More, P.G.; Bhalvankar, R.B.; Pattar, S.C. J. Indian Chem. Soc. 2001, 78, 474.

6. Pandeya, S.N.; Sriram, D.; Nath, G.; De Clercq, E. IL Farmaco 1999, 54, 624.

7. Samadhiya, S.; Halve, A., Orient. J. Chem. 2001, 17, 119.

8. Garnovskii, A.D.; Nivorozhkin, A.L.; Minkin, V.I., Coord. Chem. Rev. 1993, 126, 1.

9. Dal, H.; Süzen, Y.; Şahin, E. Spectrochim. Acta A 2007, 67, 808.

10. Rauhut, G.; Pulay, P. J. Phys. Chem. 1995, 99, 3093.

11. Scott, A.P.; Radom, L. J. Phys. Chem. 1996, 100, 16502.

12. Foresman, J.B.; Frisch, A. Exploring Chemistry with Electronic Structure Methods, 2nd ed., Gaussian, Inc.: Pittsburgh; 1996.

13. Parlak, C. J. Mol. Struct. 2010, 966, 1.

14. Alver, Ö.; Parlak, C.; Şenyel, M. Spectrochim. Acta A 2007, 67, 793.

15. Alver, Ö.; Parlak, C.; Şenyel, M. Phys. Lett. A 2007, 371, 300.

16. Alver, Ö.; Parlak, C.; Şenyel, M. Bull. Chem. Soc. Ethiop. 2009, 23, 85.

17. Alver, Ö. Magn. Reson. Chem. 2010, 48, 53.

18. Jamróz, M.H. Vibrational Energy Distribution Analysis VEDA 4, Warsaw, 2004-2010.

19. Cheeseman, J.R.; Trucks, G.W.; Keith, T.A.; Frisch, M.J. J. Chem. Phys. 1996, 104, 5497.

20. Jameson, K.; Jameson, C.J. Chem. Phys. Lett. 1987, 134, 461.

21. Frisch, M.J.; Trucks, G.W.; Schlegel, H.B.; Scuseria, G.E.; Robb, M.A.; Cheeseman, J.R.; Montgomery, J., J.A.; Vreven, T.; Kudin, K.N.; Burant, J.C.; Millam, J.M.; Iyengar, S.S.; Tomasi, J.; Barone, V.; Mennucci, B.; Cossi, M.; Scalmani, G.; Rega, N.; Petersson, G.A.; Nakatsuji, H.; Hada, M.; Ehara, M.; Toyota, K.; Fukuda, R.; Hasegawa, J.; Ishida, M.; Nakajima, T.; Honda, Y.; Kitao, O.; Nakai, H.; Klene, M.; Li, X.; Knox, J.E.; Hratchian, H.P.; Cross, J.B.; Bakken, V.; Adamo, C.; Jaramillo, J.; Gomperts, R.; Stratmann, R.E.; Yazyev, O.; Austin, A.J.; Cammi, R.; Pomelli, C.; Ochterski, J.W.; Ayala, P.Y.; Morokuma, K.; Voth, G.A.; Salvador, P.; Dannenberg, J.J.; Zakrzewski, V.G.; Dapprich, S.; Daniels, A.D.; Strain, M.C.; Farkas, O.; Malick, D.K.; Rabuck, A.D.; Raghavachari, K.; Foresman, J.B.; Ortiz, J.V.; Cui, Q.; Baboul, A.G.; Clifford, S.; Cioslowski, J.; Stefanov, B.B.; Liu, G.; Liashenko, A.; Piskorz, P.; Komaromi, I.; Martin, R.L.; Fox, D.J.; Keith, T.; Al-Laham, M.A.; Peng, C.Y.; Nanayakkara, A.; Challacombe, M.; Gill, P.M.W.; Johnson, B.; Chen, W.; Wong, M.W.; Gonzalez, C.; Pople, J.A., Gaussian 03, Revision C.02, Gaussian, Inc., Wallingford CT, 2004.

22. Frisch, A.; Nielsen, A.B.; Holder, A.J. Gaussview Users Manual, Gaussian Inc.: Pittsburgh; 2000.

23. Allen, F.H.; Kennard, O.; Watson, D.G.; Brammer, L.; Orpen, A.G.; Taylor, R. J. Chem. Soc. Perkin Trans. II 1987, S1. 